\title{
Dados anómalos
}

\author{
ALBERTO BALIL $(\dagger)^{\star}$.
}

Nuestro dado de seis caras es heredero de un largo pasado. Casi igual que en nuestros días aparece en ciudades y en tumbas romanas o helenísticas hasta el extremo que su ser parece inmutable a lo largo de los siglos. $\mathrm{Y}$, sin embargo, no es así, el dado de puntos es, en cierto modo, un advenedizo que ha sustituido frases y advertencias presentes en los dados más antiguos (Lamer 1927: 2022).

Un dado hallado en Autun (CIL XIII 100035, 24. Lafaye 1921: 127. Lamer 1927: 2022) muestra las siguientes puntuaciones

$$
\begin{aligned}
& 1+6 \\
& 2+5 \\
& 3+4 \\
& 4+3 \\
& 5+2 \\
& 6+1
\end{aligned}
$$

que dan siempre como resultado 7 .

No podemos sin embargo considerar totalmente anómalo el dado de Autun, sí lo es su sistema de puntuación, en cuanto sigue siendo un dado de seis caras y tampoco pueden considerarse anómalos los ejemplos conocidos de dados "cargados". Otra cosa son los dados de más de seis caras que correspondian a juegos que no nos son conocidos y que quizás puedan compararse a algunos de sus derivados modernos utilizados en prácticas adivinatorias. Hay que excluir en este sentido, aunque Lamer los considera como dados (Lamer 1927: 2024) los conocidos

\footnotetext{
* Universidad de Valladolid.
} 


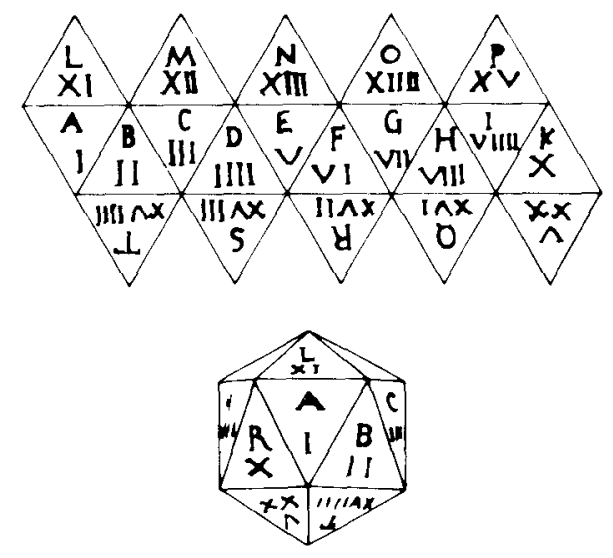

Fig. 1. Poliedro del Louvre (según Lafaye).

dodecaedros de bronce y cuya finalidad, pese al derroche de ingenio que se ha prodigado en este sentido, continúa siendo desconocida.

El British Museum posee tres dados de catorce caras, conocidos en el Reino Urido como "triple teetotum" o "four sided triple dice". Uno de ellos procede de Naucratis y solo uno presenta la numeración I-XII en cifras romanas y con el sistema aditivo.

Como dado de diecinueve caras puede considerarse un poliedro hallado por el $P$. Delattre en Cartago y que presenta la numeración $1-1 X$ y $X-C$ con exclusión del $X X$ y $L X X X$ y en el cual la numeración es, según los casos aditiva o sustractiva (Heron de Villefosse 1902: 174. Lamer 1927: 2025).

Finalmente podemos considerar aquí una serie de dados de veinte caras generalmente de procedencia oriental y numerados con cifras griegas A-Y (Lamer 1927: 1015. ¿Es el microasiático de Mowat 1897: 309.447. Heron de Villefosse 1901: 233. Michon 1904: 327?), uno egipcio del Louvre con numeración $A-Z$. Este museo posee también un ejemplar (fig. 1) con numeración griega y romana A-V y I-XX (Lafaye 1921: 128. Lamer 1927: 2026).

Nuestro propósito es ocuparnos de un octodecaedro de serpentina que perteneció a la colección Martorell y que ha sido considerado como procedente de Ampurias (Botet i Sisó 1879: 124. Hübner 1892: 6246,8. Almagro 1952: 176). Tiene caras cuadriláteras y en ellas las letras: 


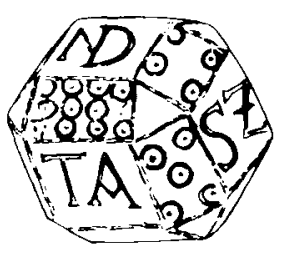

Fig. 2. Octodecaedro de la colección Martorell (según Almagro).

$\begin{array}{llllll}N G & S Z & T A & T G & N H & N D\end{array}$ y en las doce caras paralelográmicas (fig. 2) puntos del uno hasta el doce (Almagro 1952: 176).

Para las series de dos letras, Botet (Botet i Sisó 1879: 176) propuso el siguiente desarrollo que no puede ser considerado sino como rebuscado y artificioso

NG Nihil Gaudes sive Nihil Geris

SZ Z solve

TA Tibi Adfer, o Totum Abstrahe

$\mathrm{NH}$ Nihil Habeas

ND Nihil Dabis

Varios octodecaedros como este se conservaban en la colección Loustau de Besançon (Mowat 1987: 307) y en diversas localidades de Renania.

En realidad cuando se observa este octodecaedro se advierte que los tipos de letras no son romanos y que los nexos son artificiosos y las abreviaturas conducen a desarrollos forzados. Esto es lógico puesto que, como demostró Zangemeister y aceptó Michon (Michon 1904: 327 y ss.) estas abreviaturas tienen su significado en alemán y el tipo de letras se justifica en una creación del siglo XIX ejecutada sin propósito de fraude. El centro productor de estos "dados" se situa en la localidad sajona de Zoblitz y en su fábrica de objetos de serpentina. En este ambiente cobra su significado que $\mathrm{NH}$ no sea "Nihil» y menos "Nihil Habeas" sino "nimm halb" del mismo modo que NG corresponde a «nimm ganz».

Solo Lafaye (Lafaye 1921: 128) intentaria una débil defensa de los "dados de Zoblitz" basándose en la atribución de Ampurias del "octo- 
decaedro" de la colección Martorell pero la argumentación es débil. Las letras de esta pieza no corresponden en modo alguno a un tipo de escritura romana, veánse p. e. los "embellecimientos" de A y $Z$, y la procedencia supuestamente ampuritana poco o nada dice en favor de la supuesta romanidad de estos dodecaedros. Habria que preguntarse hasta que punto el incendio que destruyó la ciudad de Zoblitz en 1854 tuvo algo que ver con la repentina e imprevista, aunque de breve duración, difusión de estos octodecaedros. Las peculiaridades del comercio de antigüedades darían lugar a que uno de ellos fuera a parar a Cataluña y se le atribuyera la "autentificadora" procedencia ampuritana. De hecho ni siquiera merece el nombre de falsificación, al no existir modelo antiguo que falsear, y, al sumirse en el cajón del sastre de Instrumentum Domesticum ha permanecido semiolvidado e indiscutido. Deja ya de ilustrar una posible página sobre juegos y entretenimientos en la vieja Ampurias pero adquiere un valor de dato sobre el comercio de antigüedades en la España decimonónica. 


\section{BIBLIOGRAFIA}

Almagro, M., 1952: Las inscripciones ampuritanas griegas, ibéricas y latinas. Barcelona.

Botet I Siso, J., 1879: Noticia Histórica y Arqueológica de la Antigua Ciudad de Emporion. Madrid (y reedición de Barcelona, 1979).

HERON DE VILLEFOSSE, H., 1901: BSNAF. 1901.

-, 1902: BSNAF.

HUBNER, E., 1892: Corpus Inscriptionum Latinarum II, Supplementum. Berlin.

LAFAYE, H., 1921: Tessera lussoria, en Daremberg, Saglio, Pottier (eds.)

Dictionaire des antiquités grecques et romaines, $\mathrm{V}$. Paris.

Lamer, A., 1927: Lussoria tabula, Pauly, E. Wissowa, G. (eds.) Real Encyclopaedie des Klassisches Altertumswissenschaft 13. Munich.

MOWAT, R. E., 1897: BSNAF.

MICHON, P., 1904: BSNAF. 